\title{
The impact of ACE2 genetic polymorphisms (rs2106809 and rs2074192) on gender susceptibility to COVID-19 infection and recovery: A systematic review
}

\author{
Ahmed A. Suleiman ${ }^{1}$, Tamadher A. Rafaa ${ }^{2}$, Ali M. Alrawi ${ }^{1}$ and Mustafa F. Dawood ${ }^{3}$ \\ ${ }^{1}$ Department of Biotechnology, College of Science, University of Anbar, Ramadi, Iraq \\ ${ }^{2}$ The Presidency of the University of Anbar, Ramadi, Iraq \\ ${ }^{3}$ College of Education for Pure Science, University of Anbar, Ramadi, Iraq
}

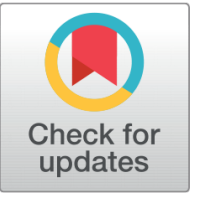

Received 09-06-2021

Revised 04-09-2021

Accepted 07-09-2021

Published 23-09-2021

\section{Corresponding Author}

Ahmed A. Suleiman

ahmed.suleiman@uoanbar.edu.iq

Department of Biotechnology, College of Science, University of Anbar, Ramadi, Iraq

DOI https://doi.org/10.47419/ bjbabs.v2i03.53

\section{Pages: $167-180$}

Distributed under the terms of the Creative Commons

Attribution-NonCommercial 4.0 International (CC-BY-NC 4.0), which permits use for any non-commercial purpose, distribution, and reproduction in any medium, provided that the original work is properly cited.

Copyright: (C) 2021 Ahmed A. Suleiman, Tamadher A. Rafaa, Ali M. Al-Rawi, Mustafa F.

Dawood

\section{ABSTRACT}

Background: Epidemiological studies revealed there is a difference in susceptibility to infection with severe acute respiratory syndrome coronavirus 2 (SARS-CoV-2) because of differences in gender with age and males being more inflicted. There is a clear indication that deaths caused by coronavirus disease 2019 (COVID-19) in males appeared at a higher rate than females across 35 nations. The implication of associated disease-risk genes, involved in the susceptibility of COVID-19 such as the angiotensin-converting enzyme 2 (ACE2), has recently received considerable attention due to their role in severe injury of lung and mediated SARS-CoV-2 entry as a host receptor.

Objectives: Herein, we aimed to systematically review how two main genetic polymorphisms of ACE2 (rs2106809 and rs2074192) can affect the gender susceptibility to SARS-CoV-2 infection.

Methods: To conduct this systematic review, a literature search in PubMed, Google Scholar, ScienceDirect, and Nature was made for the period 2004 to 2020 . We searched for the impact of ACE2 genetic polymorphisms (rs2106809 and rs2074192) on gender susceptibility.

Results: We noticed that there was a differential genotype distribution between males and females in various global populations whereas mutant variants were common in males compared to wild-type variants among females which may reflect differences in gender susceptibility to infection with SARS-CoV-2. Females are less susceptible to coronavirus as compare to males because of the expression of ACE2 receptor. It has a double role in favour of COVID-19 and against COVID-19. Conclusions: Male mortality is greater than female mortality, which might be attributed to the ACE2 deficiency in women. Epidemiological studies have shown that the differences in sex and age have different susceptibility to SARS-CoV-2 infection.

Keywords ACE2, COVID-19, gene polymorphism, gender, SARS-CoV-2

\section{OPEN ACCESS}




\section{INTRODUCTION}

Coronaviruses, a family of disease-causing viruses, responsible for diseases that threaten the humans on the earth such as severe acute respiratory syndrome (SARS), ${ }^{1}$ Middle East Respiratory Syndrome (MERS), ${ }^{1,2}$ and the recently declared coronavirus disease 2019 (COVID-19); ${ }^{3}$ and all are ranging from the mild to very severe pneumonia. The severe acute respiratory syndrome coronavirus 2 (SARS-CoV-2), the causative agent of COVID19 , is single strand RNA (ssRNA) virus comprmised of glycoprotein spikes, mediating the virus to enter in host cells. ${ }^{4}$ Recently, both epidemiological ${ }^{5}$ and experimental ${ }^{6}$ features of COVID-19 patients have been defined. In hypertensive patients, diabetics, obese, and the elderly, recent researches have shown a greater risk of infection. ${ }^{7}$ However, little evidence on the impact of ACE2 genetic polymorphisms on gender susceptibility to infection and the rate of COVID-19 are available.

Phylogenetic research has led scientists to explore the host entry process of SARS-CoV-2 and found that it enters into the host cell by binding to ACE2 membrane receptors. ${ }^{8}$ Body parts including the respiratory tract, stomach, small intestine, skin, thymus, spleen, liver, bone marrow, and blood vessels are all vulnerable to COVID-19 infection due to an abundance of ACE2. ${ }^{9}$ In lung alveolar epithelial cells, ACE2 is expressed in larger amounts. Thus, it contributes in damaging the lungs in acute respiratory distress syndrome (ARDS) and pneumonia. ${ }^{10}$ SARS-CoV-2 has also been shown to form an association with the reninangiotensin-aldosterone system (RAAS) via (ACE2) enzyme. ${ }^{11}$

Angiotensinogen is a key substrate for RAAS, which made in the liver, and split to produce angiotensin 1 (also called pro-angiotensin), by the renin. The body has vasodilatory, anti-inflammatory and antioxidant properties attributed to the ACE2. ${ }^{12}$ The ACE2 catalytic domain is the extracellular portion of the cell, which can be destroyed, followed by the release of ADAM17 (metallopeptidase and disintegrin) into the blood Figure $1 .{ }^{13}$ The association between ACE2 and SARS-CoV-2 has an important involvement and relationship to the severity of infection developing in the human body Figure $2 .{ }^{14}$

Furthermore, SARS-CoV-2-mediated infection has been shown to vary according to differences in age. For instance, elder patients are more vulnerable than children to COVID19. Knowing this relationship will pave a way for inventors and investigators to develop better options, assisting in the treatment of COVID-19. A study points out the possible sources of improved confrontation to COVID19 in youngsters compared to grownups due to ACE2 expression components, the double role of ACE2 in defending lesions (inflammatory) along with detrimental effects of ACE2 which act as a molecular aim in promoting the virus entry. The objective of the authors is to provide evidence on the activities of the ACE2 enzyme in contradiction of or in service of the progression of COVID-19 to demonstrate the complexity of ACE2 enzyme behaviour during illness, this facilitates researchers' chance to create safe vaccines and solutions for therapeutics. In turn, the study of the roles of ACE2 in different age groups, will also promote clarity, and study the receptor behavior in the present situation. ${ }^{15}$ The ACEs is one of the exopeptidases, which might be common to several peptides. It is predominantly found in the cell membrane, and firstly 
A)

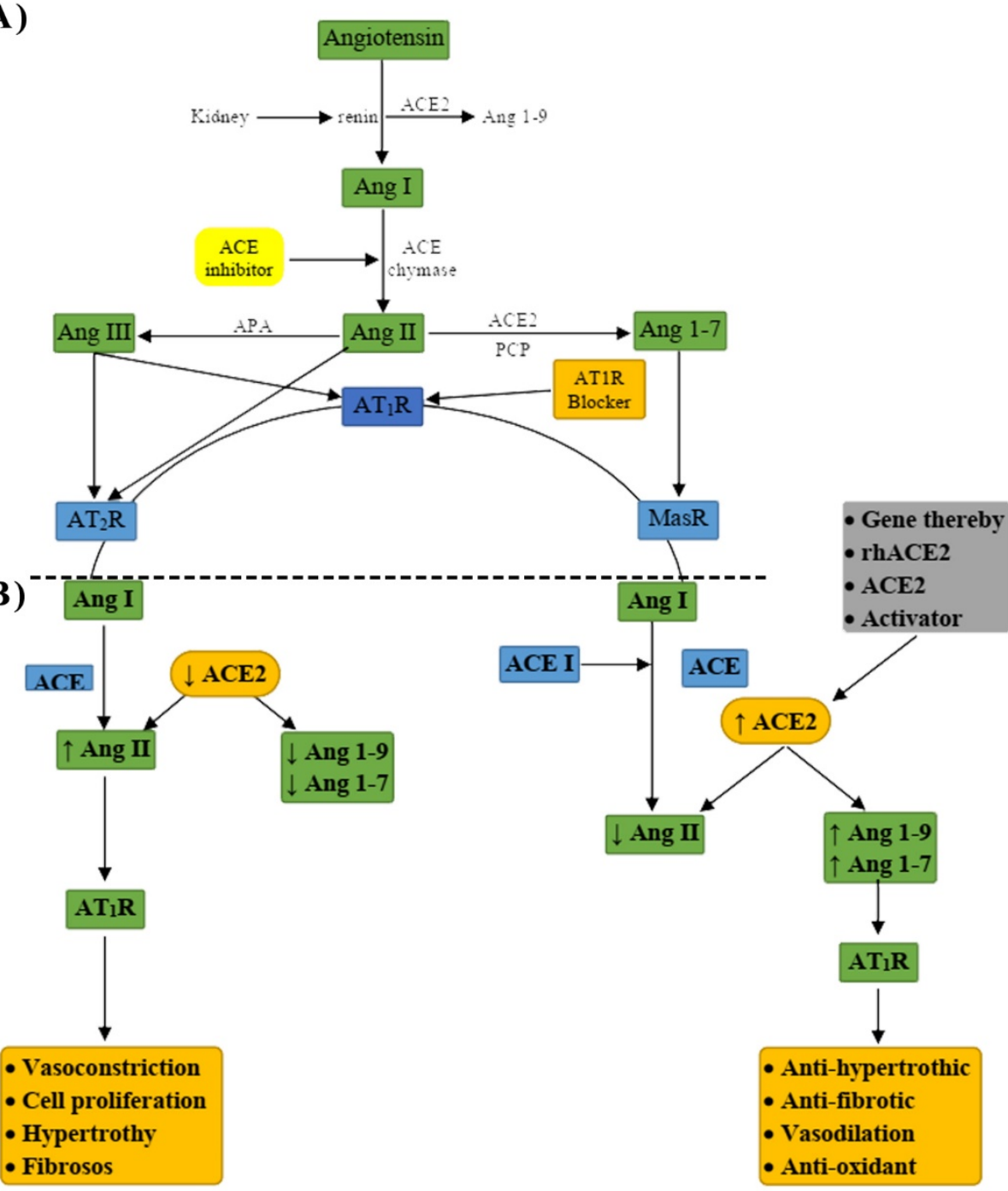

Figure 1 The enzymaticflow of the renin-angiotensin system (RAS) depicts the main receptor systems, the biological activities of angiotensin 2 and Ang-(1-7), and the stability of ACE and ACE2. ${ }^{7}$ A). RAS system showing the angiotensin peptide metabolic pathway as the initiator compound cleaved by renin (kidney) to form Ang 1 followed by ACE's followed by Ang 2 to Ang (1 to 7) facilitated cleavage of ACE2. Ang 2 functions on the receptors of AT1 and AT2, while Ang (1 to 7) operates on the receptors of Mas and antagonizes the activities of the axis of Ang2/AT1R. B) Curbed ACE2 levels result in a balance change in the RAS to the Ang 2/AT1R (activator) axis, promoting the progression of the infection. Improved levels of ACE2 change the balance to the Ang (1 to 7)/MasR axis (inhibitor) via rhACE2, ACE2 activators, resulting in defence from viral infection. 


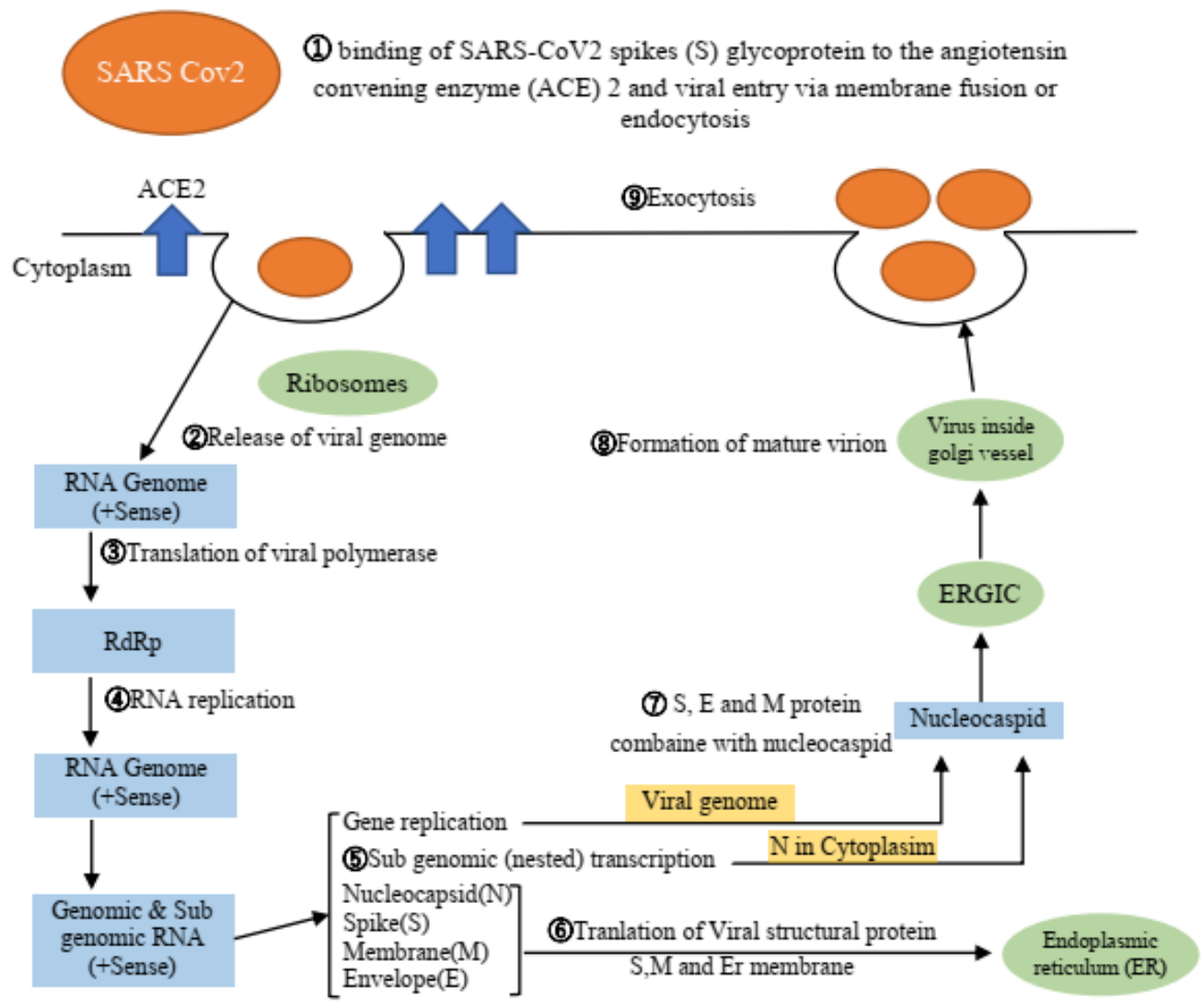

Figure 2 Way of the entrance of the SARS-CoV-2 to host cell. ${ }^{7}$ The protein $S$ of the virus attaches to the human ACE2 receptor, when receptor-binding domain, human proteases triggered. It makes its way into the cell via the endosomal path. Then, viral RNA is translation and cytoplasm of ORF1a and considered to generate ppla in additional pplab polyproteins. RTC proteases cleave these proteins, which promote the expansion of full length (-) RNA copies and RNA replicas and function as for full length (+) RNA genomes templates. A collection sub-genomic RNAs formed by fragmented transcription, with frequent open reading frames, Only the nearest ( $5^{\prime}$ end) is translated in this case. After the synthesis of viral structural proteins, the nucleocaspids are assembled in the cytoplasm. After that, there's endoplasmic reticulum and Golgi apparatus budding through the lumen of the intermediate compartment. This is accompanied by releasing virions from the infested cell-mediated by exocytosis.

reported in the year 2000. ${ }^{16}$ This discovery gave the angiotensin 2 attention, a dynamic peptide often referred to as angiotensin-(1-8). This is the basic cause of facilitating events including increased vasoconstriction, pro-inflammatory action, pro-fibrosis, and stimulation of aldosterone secretion by binding to angiotensin 1 (AT1) receptor. ACE2 works by deactivating angiotensin 2 and then converting it to angiotensin. ${ }^{17}$

Similarly, this active peptide inhibits angiotensin 2's activity. Moreover, aminopeptidases enzyme is shown to deactivate angiotensin 2 , it regulates the conversion of angiotensin 2 into angiotensin 3, resulting in activities like with angiotensin 2 receptors and an affinity of 30 times greater than that of AT1 receptors, ${ }^{17}$ resulting in effects such as increased natriuresis 
and bradykinin, besides a vasodilation. ${ }^{18}$

These components form an integral part of the process of renin-angiotensin aldosterone, consisting of pathways for initialization and prevention. Here the forthcoming consists of the receptor pathway for angiotensin 2 or angiotensin 1 or ACE1 or aldosterone, while the latter consists of the receptor pathway for angiotensin (1-7) or ACE2 or Mas, where the preventer pathway act as a blocker for the action of angiotensin 2 in the way for the initiator. Furthermore, ACE2 has been discovered to interact with AT1 receptors, angiotensin 2 receptor blockers have targeted these receptors, which are mediated by angiotensin 2 , are opposed to the actions caused by this receptor, thus occupying the angiotensin 2 interaction site. This in turn, stimulates angiotensin 2 liberation, this is accompanied by enhanced ACE2 enzyme expression in the body. As indicated by sex-disaggregated information incorporated by worldwide scientists, there is a clear indication that coronavirus-related deaths with males appeared at a higher rate than females across 35 nations (Worldwide Health 50/50). For example, the extent of deaths among people adds up to $13.3 \backslash 7.4$ in Italy, $4.7 \backslash 2.8$ in China, 8.4 \4.7 in Spain, 10.6\6.6 in The Netherlands), and 4.0 1.7 in Ireland. Gender equality index finding revealed also that women are at a greater risk of infection than males due to multiple factors: women commute via public transport, do grocery shopping, and sometimes dominate many professions Epidemiology studies revealed different gender and age have different susceptibility to contagion with SARS-CoV-2 with males and older age being the most inflicted. ${ }^{19}$ The implication of associated disease risk genes involved in the susceptibility of COVID-19 such as the ACE2 has recently received good attention due to its role in the acute injury of lungs. ${ }^{20}$ The genetic variants of ACE2 showed to be correlated with mixing angiotensin-(1-7) stages in females suffering from high blood pressure. ${ }^{21}$ ACE2 was made to work as a SARS-CoV-2 receptor. The gene ACE2 showed effective genetic polymorphisms among a different population around the globe which may influence the susceptibility to infection and/or disease progression to COVID- $19 .{ }^{20}$ In this regard, this study sought to explore whether the genetic polymorphism in the ACE2 gene, particularly rs2106809 and rs2074192 would explain the genetic differences between males and females toward infection with SARS-CoV-2 in various parts of the world. The sex variations can be explained by multiple X-linked genes. fAmongst the main savouries of the lethality of the virus are cardiovascular comorbidities. The number of non-genetic, sex-independent factors to alter vulnerability and mortality is enormous, with many others consisting on gender and cultural habits from various countries, should be considered. There are a few women dying, (young and elderly) than males (age-fellow). Actually, a series of possible methods can enlighten that why women are less susceptible toward serious COVID-19 infections. This is because the involvement of two factors including the transmembrane protease serine 2 and ACE2, may be considered first of all. ${ }^{22}$

Although the receptor for the S protein of coronavirus is ACE2. The organs that are mainly targeted by SAR-CoV-2 contain ACE2. ACE2 has been suggested as a modulator of SARS-CoV-2 exposure in both sexes. ${ }^{23}$ The location of ACE2 is the X chromosome and in sites commonly escaping the inactivation of one $\mathrm{X}$ chromosome. ${ }^{24}$ It is also possible that this plays a significant role in women's defence system. It is hypothesized that, for example, 
by encouraging coronavirus binding, the $2 \mathrm{nd} \mathrm{X}$ chromosome may shield women from lethal polymorphisms that make COVID-19 more violent in men. Certainly, in a current report, weaker results in elder COVID-19 patients were due to the existence of lower ACE-2 levels and subsequent upregulation of proinflammatory pathways of angiotensin II (Ang II) in the body, which may render patients more vulnerable to systemic 'deleterious' Ang II effects. ${ }^{14}$ In almost a yin/yang phase, ACE and ACE2 are produce, Ang II and Ang-1-7 are connected to one other after there is a vice versa relationship in their quantity one increases another decrease. $^{25}$

Viruses enter into host cells due to ACE2, however, over expression can defend against harm (by decreasing Ang II and forming Ang-1-7). And, ACE2 exhibits metalloproteinase 17 (ADAM17) can "shed" ACE2 from endothelial cells, This causes the release of bioactive and catalytic ectodomains into the circulation. Therefore, the ACE/ACE2 ratio is changed in different tissues, membrane-bound soluble, and the role of ACE2 is complicated. For example, it has been suggested that by restricting its attachment to cellular ACE2. ${ }^{26}$ Coronavirus could be reduced by soluble ACE2. However, Sama and colleague showed that in patients with heart failure (HF), males are associated with higher ACE2 plasma levels. ${ }^{27}$ Nevertheless, the authors agree that there is no proof that there is a connection between membranebound ACE2 levels and shedding enzymes in the two genders. In fact, with preserved and reduced ejection, HF contains a higher amount of soluble ACE2 ejection fraction. ${ }^{28}$ Also, the expression of ACE2 tends to be decreased in postmenopausal women. ${ }^{29}$ Stimulatingly, transgender men subjected to treatments show substantially high (ACE2) levels expression and a high amount of Sertoli cells communicating ACE2 in the testis. Estrogens and androgens are declining by the passage of time, ${ }^{30}$ this weakening is likely to lead to a decrease in ACE2 expression with ageing in both genders. The study of 2017 showed there are no differences in the two genders in the activity of serum of ACE and ACE2, although lower serum activity of ACE2 was observed in newer relative to older women. ${ }^{31}$ Overall, differences in ACE and ACE2 expression can tend to specific to organs and age-dependent in both genders, in animals ${ }^{32}$ and humans with a less obvious function in soluble ACE2 ${ }^{26}$. It is a matter of investigation whether the level of ACE2 in the lungs are linked to the vulnerability and harshness of COVID-19. ${ }^{33}$ It was stated in a preprint red-top that monomers may have advanced ACE2 expression in the lungs compared to women, ${ }^{34}$ with potentially significant implications for COVID-19 infections, as the SARS-CoV-2 enter via respirational tract. However, enlarged permeability of capillary, clotting, fibrosis, and death of alveolar cells observed in both SARS and COVID-19.Explained by polymorphisms in ACE and $A C E 2$ genes. ${ }^{35}$ Lung damage and respiratory failure can be explained by these effects. The role of ACE2 in COVID-19 is not completely clear but most evidence suggests that it may be advantageous to have a low membrane-bound ACE/ACE2 ratio. Certainly, ACE may be pro-inflammatory and pro-oxidant, whereas antioxidant and anti-inflammatory effects can be mediated by ACE2. In HF, soluble ACE2 is higher; it is not yet clear whether this is defensive or harmful or is just an epiphenomenon. Nevertheless, by controlling the activity of the ADAM17 enzyme, inhibition of ACE2 shedding has been advised as a possible beneficial solution for heart failure. ${ }^{28}$ As the ACE2 expression on chromosome $\mathrm{X}$ affected 
by estrogens across the body, the ratio of ACE/ACE2 can transfer more in women than in men to the ACE2/Ang 1 to 7/MAS receptor axis. This may explain why women are shielded from the outcome of extreme COVID-19. We must understand, however, that there are variations in the $\mathrm{ACE} / \mathrm{ACE} 2$ ratio that are tissue- and organ-specific, which can also be affected by exercise and medical conditions. It is not so far clear whether the deadliness of SARS-CoV-2 is primarily due to the access and duplication of viruses or to an exaggerated inflammatory response. ${ }^{36}$ Numerous additional genes linked to $\mathrm{X}$ and $\mathrm{Y}$ can also explain gender differences. ${ }^{37} \mathrm{X}$ and $\mathrm{Y}$ chromosome-encoded immune regulatory genes can clarify inferior virus-related loads and inflammation to decrease in women as compared to men. ${ }^{38}$ The two X chromosomes control the immune system even though one of them is inactive. As well as moderating other proteins, including CD40L, CXCR3, and TLR8, the X chromosome controls the immune system. These can be high-regulated in females and the response to both virus-related contagions and vaccines can be calculated. To recognize a precise gene name describing SARS-CoV-2 contagion differentially expressed genes (DEGs) network was developed. ${ }^{39}$ In addition, in modulating the intensity of COVID-19, gender differences in immune response, strong-minded by genetic factors, and hormones, ${ }^{37}$ can play a significant role. The number of $\mathrm{CD} 4+\mathrm{T}$ cells also varies between genders, with women with a stronger immune response being higher. ${ }^{38}$ Lastly, non-genetic, gender-independent features can change vulnerability and death is huge, numerous additional factors, including gender and cultural behaviours, are likely to be considered in different countries. For example, there was a high in females because of social and religious activities (Report on the Epidemiological Characteristics of Coronavirus Disease 2019. Additional gender-related custom and an independent risk factor for worsening COVID-19 could be smoking. Smoking ratio and function ACE/ACE2 is not clear.ACE2 increase and enzyme activity decrease have been identified in numerous readings. ${ }^{40}$ We may risk that high levels of (ACE2) may enable entry of most viruses, while downregulation of ACE2 may clarify the severity of COVID-19 in smokers, at least in part. ${ }^{41}$ This study attempted to provide an answer for the variable infection and mortality rates of the SARS-CoV-2 between males and females worldwide

\section{MATERIALS AND METHODS Literature search and strategy}

A systematic literature search was conducted on September 2020 in reputed literature databases and search engines (PubMed, Google Scholar, ScienceDirect, and Nature) by applying these keywords: (ACE), (ACE2), (COVID-19), (Polymorphism), (SNP), we conducted research and extracted the data that was relevant to research topic.

A total of 150 research paper were retrieved from all the above-mentioned databases. From all these 150 publications, 30 research paper were closely related to our research topic after reading the paper's title and abstract.

It is not yet known whether this differential rate of susceptibility between genders to infection/mortality of SARS-CoV-2 is attributed to the genetic variants of the main host 
receptor ACE2 in various ethnic populations. Therefore, two main genetic polymorphisms (rs2106809 and rs2074192) were screened and analyzed using previously published papers. All reviews, reports, opinions, commentaries, and non-full length research papers were excluded.

\section{Data extraction and quality evaluation}

The screening process was conducted independently by (title, abstract, full-text and data extraction) by three authors (AAS, TAR, and AMA), and in the event of a discrepancy between the three authors, the MFD is referred to as a co-creator of the consensus. The authors reviewed the full text of the article for further information and clarification when there is insufficient data. Data from eligible studies were extracted and summarized in an excel spreadsheet. The following information was extracted for each of the included studies: district name, study design, study area/city, study period, study design, sample types, study population, number of study participants.

\section{Quality assessment}

The quality of the included studies was checked independently by two authors (AAS and MFD) using a set of pre-defined criteria such as quality of research design, and completeness of extractable information.

\section{RESULTS AND DISCUSSION}

A total of 150 items were collected from all the databases mentioned previously. From these publications, 30 papers closely related to the topic of our study were selected. It was found that 6 researches ${ }^{2,5,6,39,42,43}$ match the objective of our study. The rest of the researches were only neglected for several reasons, including the small number of study participants, lack of focus on race, and non-full length articles.

By analyzing public data, it was found that the two SNPs (rs2106809 and rs2074192) were expressed at variable proportions among different ethnic population around the world ${ }^{11}$. A summary of these findings as outlined in Table 1. The prevalent genotypes of rs2074192 among Caucasian males were almost dominated by TT mutant genotypes whereas CC or CT genotypes were common in females. On the other hand, the genotype trend was changed in the Asian female population as CC or CT (no mutant genotypes were observed) with no considerable difference among males than those observed with Caucasian. A similar pattern for the rs 2106809 genotypes particularly among females in the Middle East and India. Taken together for both genetic polymorphisms, it appeared that males had a mutant genotype 
compared to either wild or heterozygous mutant in females. Considering the limitation of sample size number, these data may suggest that the mutant genotype among males could contribute to the severity of infection in males compared to females around the world but the absence of such variants in females may explain the low infectivity/mortality rate seen among them.

\section{CONCLUSIONS}

Many factors may affect COVID-19 infection and recovery such as immune response, smoking, and genetic alteration in many genes including ACE2. Females are less affected as compared to males because ACE2 gene is located on $\mathrm{X}$ chromosome and females have two copies of ACE2. This research is all about ACE2 and its impact on the gender susceptibility to infection and rate of recovery COVID-19. Patient body parts e.g. lungs, small intestine, stomach, liver blood vessels, bone marrow, skin, oral, nasal mucosa and kidney are most affected due to the presence of ACE2 which is the receptor of COVID-19. RAAS has been made in the liver and split into renin for angiotensin 1 development which activated angiotensin 2 by ACE. ACE2 counters vasoconstrictions and pro-inflammatory activities which are opposed by ACE result. Elder patients are more vulnerable than children to COVID-19. Epidemiology studies showed different gender and age have different susceptibility to contagion with SARS-CoV-2. ACE2 exhibited a high degree of genetic polymorphisms among a different population around the world. Both rs2106809 and rs2074192 would explain the genetic differences between males and females toward COVID-19. TMPRSS2 splits the S-protein preferring virus attachment to the cell membrane.

\section{ABBREVIATIONS}

ACE2, angiotensin-converting enzyme; ARDS, acute respiratory distress syndrome; CDC, Disease Control and Prevention; HF, heart failure; NA, not available; RAAS, renin-angiotensin-aldosterone system; SARS, severe acute respiratory syndrome; ssRNA, single-stranded ribonucleic acid.

\section{ACKNOWLEDGEMENTS}

The authors would like to express deep thanks to the University of Anbar, College of Science, Department of Biotechnology for their support in access for articles. 


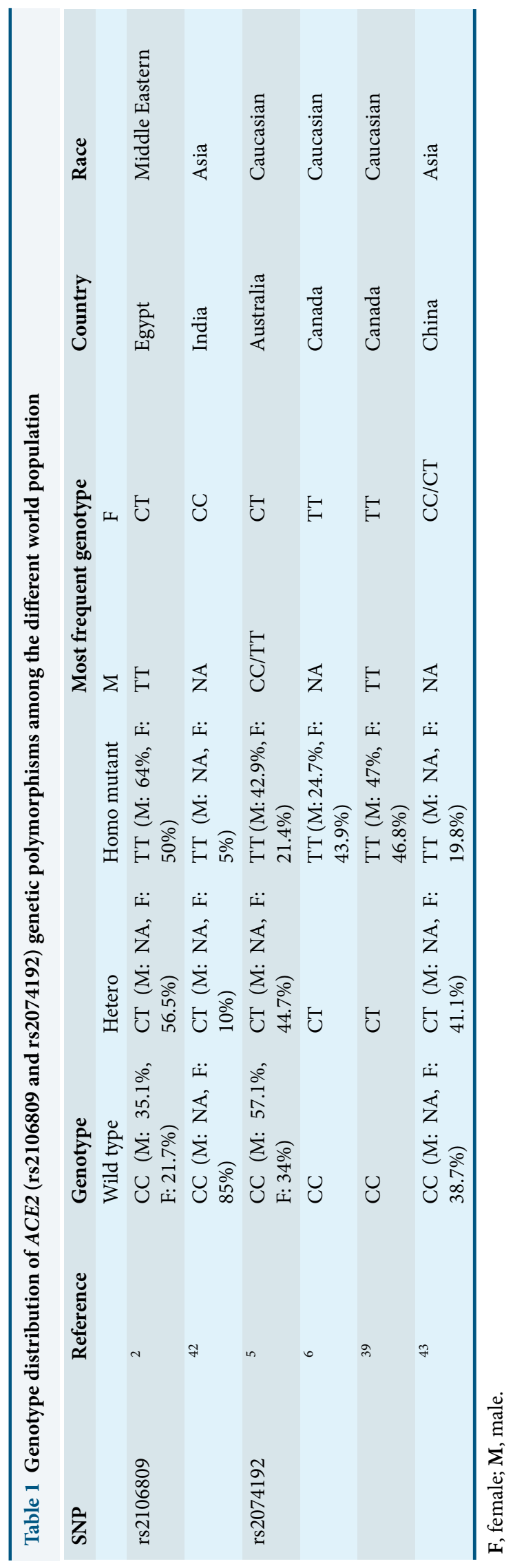




\section{DECLARATIONS}

\section{Authors' contributions}

All the author looks on the original idea and contributed to data collection, analysis, and interruptions.

\section{Conflict of interest}

Not declared.

\section{Ethical approvals}

Not applicable for systematic reviews.

\section{Data availability}

Author is only responsible for the data in this script which may not reflect the opinion or policy of the journal.

\section{Funding resources}

This work didn't receive any fund.

\section{REFERENCES}

1. Jin JM, Bai P, He W. Gender Differences in Patients With COVID-19: Focus on Severity and Mortality. Front Public Heal. 2020;8:1-6. Available from: 10.3389/ fpubh.2020.00152.

2. Houssen M, Al-Harass M, Shahin D, Etreby SE, Farag K, Ebrahim MA, et al. Association of ACE and ACE2 Genes Polymorphisms With Susceptibility To Hepatocellular Carcinoma in Egyptian HCV Patients. J Glob Biosci. 2015;4:2393-2403.

3. Salman JS, Mahmood NN, Abdulsattar BO, Abid HA. The Effectiveness of Probiotics against Viral Infections: A Rapid Review with Focus on SARS-CoV-2 Infection. Open Access Maced. J Med Sci. 2020;8(T1):496-508. Available from: 10.3889/ oamjms.2020.5483.

4. Ramchand J, Patel SK, Srivastava PM, Farouque O, Burrell LM. Elevated plasma angiotensin converting enzyme 2 activity is an independent predictor of major adverse cardiac events in patients with obstructive coronary artery disease. PLoS One. 2018;13(6):1-11. Available from: 10.1371/journal.pone.0198144.

5. Patel SK, Wai B, Ord M. Association of ACE2 genetic variants with blood pressure, left ventricular mass, and cardiac function in caucasians with type 2 diabetes. Am J Hypertens. 2012;25(2):216-222. Available from: 10.1038/ajh.2011.188.

6. Malard L, Kakinami L, O'loughlin J. The association between the angiotensinconverting enzyme-2 gene and blood pressure in a cohort study of adolescents. BMC Med Genet. 2013;14(1). Available from: 10.1186/1471-2350-14-117. 
7. Behl T, Kaur I, Bungau S. The dual impact of ACE2 in COVID-19 and ironical actions in geriatrics and pediatrics with possible therapeutic solutions. Life Sci. 2020;257:118075-118075. Available from: 10.1016/j.lfs.2020.118075.

8. Tan W, Aboulhosn J. The cardiovascular burden of coronavirus disease 2019 (COVID-19) with a focus on congenital heart disease. Int J Cardiol. 2020;309:70-77. Available from: 10.1016/j.ijcard.2020.03.063.

9. Ciaglia E, Vecchione C, Puca AA. COVID-19 Infection and Circulating ACE2 Levels: Protective Role in Women and Children. Front Pediatr. 2020;8:11-13. Available from: 10.3389/fped.2020.00206.

10. Zhang H, Baker A. Recombinant human ACE2: Acing out angiotensin II in ARDS therapy. Crit Care. 2017;21(1):4-6. Available from: 10.1186/s13054-017-1882-z.

11. Bourgonje AR, Abdulle AE, Timens W. Angiotensin-converting enzyme 2 (ACE2), SARS-CoV-2 and the pathophysiology of coronavirus disease 2019 (COVID-19). J Pathol. 2020;251(3):228-248. Available from: 10.1002/path.5471.

12. Datta PK, Liu F, Fischer T, Rappaport J, Qin X. SARS-CoV-2 pandemic and research gaps: Understanding SARS-CoV-2 interaction with the ACE2 receptor and implications for therapy. Theranostics. 2020;10(16):7448-7464. Available from: 10.7150/thno.48076.

13. Grobe JL, Buehrer BA, Hilzendeger AM. Angiotensinergic signaling in the brain mediates metabolic effects of deoxycorticosterone (DOCA)-salt in C57 mice. Hypertension. 2011;57(3 PART 2):600-607. Available from: 10.1161/ HYPERTENSIONAHA.110.165829.

14. Kuba K, Imai Y, Rao S. A crucial role of angiotensin converting enzyme 2 (ACE2) in SARS coronavirus-induced lung injury. Nat Med. 2005;11(8):875-879. Available from: $10.1038 / \mathrm{nm} 1267$.

15. Dhochak N, Singhal T, Kabra SK, Lodha R. Pathophysiology of COVID-19: Why Children Fare Better than Adults? Indian J Pediatr. 2020;87(7):537-546. Available from: 10.1007/s12098-020-03322-y.

16. Donoghue M, Hsieh F, Baronas E. A Novel Angiotensin-Converting Enzyme Related to Angiotensin 1-9. Circ Res. 2000;87(5):1-10.

17. Minhas AS, Scheel P, Garibaldi B, Liu G, Horton M, Jennings M, et al. Takotsubo Syndrome in the Setting of COVID-19. JACC Case Rep. 2020;2(9):1321-1325. Available from: 10.1016/j.jaccas.2020.04.023.

18. Pyrc K, Berkhout B, Hoek LVD. Identification of new human coronaviruses. Expert Rev Anti Infect Ther. 2007;5(2):245-253. Available from: 10.1586/14787210.5.2.245.

19. Chen Y, Liu Q, Guo D. Emerging coronaviruses: Genome structure, replication, and pathogenesis. J Med Virol. 2020;92(4):418-423. Available from: 10.1002/jmv.25681.

20. Imai $Y$, Kuba K, Rao S. Angiotensin-converting enzyme 2 protects from severe acute lung failure. Nature. 2005;436(7047):112-116. Available from: 10.1038/nature03712.

21. Chen N, Zhou M, Dong X. Epidemiological and clinical characteristics of 99 cases of 2019 novel coronavirus pneumonia in Wuhan, China: a descriptive study. Lancet. 2020;395:507-513. Available from: 10.1016/S0140-6736(20)30211-7. 
22. Cheng P, Zhu H, Witteles RM. Cardiovascular Risks in Patients with COVID-19: Potential Mechanisms and Areas of Uncertainty. Curr Cardiol Rep. 2020;22(5):1-6. Available from: 10.1007/s11886-020-01293-2.

23. Hoffmann M, Kleine-Weber H, Schroeder S. SARS-CoV-2 Cell Entry Depends on ACE2 and TMPRSS2 and Is Blocked by a Clinically Proven Protease Inhibitor. Cell. 2020;181(2):271-280. Available from: 10.1016/j.cell.2020.02.052.

24. Fisher S, Barry A, Abreu J. A scalable, fully automated process for construction of sequence-ready human exome targeted capture libraries. Genome Biol. 2011;12(1):1-15. Available from: 10.1186/gb-2011-12-1-r1.

25. Wakahara S, Konoshita T, Mizuno S. Synergistic expression of angiotensinconverting enzyme (ACE) and ACE2 in human renal tissue and confounding effects of hypertension on the ACE to ACE2 ratio. Endocrinology. 2007;148(5):2453-2457. Available from: 10.1210/en.2006-1287.

26. Monteil V, Kwon H, Prado P. Inhibition of SARS-CoV-2 Infections in Engineered Human Tissues Using Clinical-Grade Soluble Human ACE2. Cell. 2020;181(4):905913. Available from: 10.1016/j.cell.2020.04.004.

27. Sama IE, Ravera A, Santema BT, van Goor H, Maaten JMT, Cleland JGF, et al. Circulating plasma concentrations of angiotensin-converting enzyme 2 in men and women with heart failure and effects of renin-angiotensin-aldosterone inhibitors. Eur Heart J. 2020;41(19):1810-1817. Available from: 10.1093/eurheartj/ehaa373.

28. Patel VB, Zhong JC, Grant MB, Oudit GY. Role of the ACE2/angiotensin 1-7 axis of the renin-angiotensin system in heart failure. Circ Res. 2016;118(8):1313-1326. Available from: 10.1161/CIRCRESAHA.116.307708.

29. Gagliardi MC, Tieri P, Ortona E, Ruggieri A. ACE2 expression and sex disparity in COVID-19. Cell Death Discov. 2020;6(1):1-2. Available from: 10.1038/s41420-0200276-1.

30. Horstman AM, Dillon EL, Urban RJ, Sheffield-Moore M. The role of androgens and estrogens on healthy aging and longevity. Journals Gerontol - Ser A Biol Sci Med Sci. 2012;67(11):1140-1152. Available from: 10.1093/gerona/gls068.

31. Fernández-Atucha A, Izagirre A, Fraile-Bermúdez AB. Sex differences in the aging pattern of renin-angiotensin system serum peptidases. Biol Sex Differ. 2017;8(1):1-8. Available from: 10.1186/s13293-017-0128-8.

32. Xudong X, Junzhu C, Xingxiang W, Furong Z, Yanrong L. Age- and gender-related difference of ACE2 expression in rat lung. Life Sci. 2006;78(19):2166-2171. Available from: 10.1016/j.lfs.2005.09.038.

33. Gheblawi M, Wang K, Viveiros A. Angiotensin-Converting Enzyme 2: SARS-CoV2 Receptor and Regulator of the Renin-Angiotensin System: Celebrating the 20th Anniversary of the Discovery of ACE2. Circ Res Published. 2020;p. 1456-1474. Available from: 10.1161/CIRCRESAHA.120.317015.

34. Zhao Y, Zhao Z, Wang Y, Zhou Y, Ma Y, Zuo W. Single-cell RNA expression profiling of ACE2, the receptor of SARS-CoV-2. bioRxiv. 2020;Available from: 10.1101/2020. 01.26.919985. 
35. Gemmati D, Bramanti B, Serino ML, Secchiero P, Zauli G, Tisato V. COVID-19 and individual genetic susceptibility/receptivity: Role of ACE1/ACE2 genes, immunity, inflammation and coagulation. might the double $\mathrm{x}$-chromosome in females be protective against SARS-COV-2 compared to the single $\mathrm{x}$-chromosome in males? Int J Mol Sci. 2020;21(10):1-23. Available from: 10.3390/ijms21103474.

36. Chappell MC, Marshall AC, Alzayadneh EM, Shaltout HA, Diz DI. Update on the angiotensin converting enzyme 2-angiotensin (1-7)-Mas receptor axis: Fetal programing, sex differences, and intracellular pathways. Front Endocrinol (Lausanne). 2014;5:1-13. Available from: 10.3389/fendo.2013.00201.

37. Ghosh S, Klein RS. Sex Drives Dimorphic Immune Responses to Viral Infections. J Immunol. 2017;198(5):1782-1790. Available from: 10.4049/jimmunol.1601166.

38. Conti P, Younes A. Coronavirus cov-19/sars-cov-2 affects women less than men: Clinical response to viral infection. J Biol Regul Homeost Agents. 2020;34(2):339343. Available from: 10.23812/Editorial-Conti-3.

39. Fagone P, Ciurleo R, Lombardo SD. Transcriptional landscape of SARS-CoV-2 infection dismantles pathogenic pathways activated by the virus, proposes unique sexspecific differences and predicts tailored therapeutic strategies. Autoimmun Rev. 2020;19(7):102571-102571. Available from: 10.1016/j.autrev.2020.102571.

40. Yuan YM, Luo L, Guo Z, Yang M, Ye RS, Luo C. Activation of renin-angiotensinaldosterone system (RAAS) in the lung of smoking-induced pulmonary arterial hypertension (PAH) rats. JRAAS - J Renin-Angiotensin-Aldosterone Syst. 2015;16(2):249-253. Available from: 10.1177/1470320315576256.

41. Penna C, Mercurio V, Tocchetti CG, Pagliaro P. Sex-related differences in COVID19 lethality. Br J Pharmacol. 2020;177(19):4375-4385. Available from: 10.1111/bph. 15207.

42. Wang SX, Fu CY, Zou YB, Wang H, Shi Y, Xu XQ, et al. Polymorphisms of angiotensin-converting enzyme 2 gene associated with magnitude of left ventricular hypertrophy in male patients with hypertrophic cardiomyopathy. Chin Med J (Engl). 2008;121(1):27-31. 18208662.

43. Ghafouri-Fard S, Noroozi R, Omrani MD, Branicki W, Pośpiech E, Sayad A, et al. Angiotensin converting enzyme: A review on expression profile and its association with human disorders with special focus on SARS-CoV-2 infection. Vascul Pharmacol. 2020;130(106680). Available from: 10.1016/j.vph.2020.106680. 